\title{
The Impact of COVID-19 on Agricultural Economy and Countermeasures
}

\author{
Yuxian $\operatorname{Han}^{1}$ \\ ${ }^{1}$ School of European and Latin American Studies, Shanghai International Studies University, Shanghai, 201620, \\ China \\ Corresponding Author's Email: kimjisoo12138@163.com
}

\begin{abstract}
In 2020, COVID-19 broke out worldwide, which greatly impacted the global economic market. This paper, adopting qualitative analysis method, mainly studies the impact of the epidemic on basic agricultural products, cash crops and high value-added agricultural products, and puts forward some suggestions on how to respond to such challenges for agricultural economy in similar global health emergencies, and offers some follow-up suggestions.
\end{abstract}

Keywords: Economical Economy, COVID-19, Basic Agricultural Products, Cash Crop, High Value-added Agricultural Products, Impact.

\section{INTRODUCTION}

\subsection{Background}

In February 2020, the time of the Chinese Lunar New Year, COVID-19 broke out in China. During this time, the flow of people was heavy. To cut off the spread of the epidemic, the state took resolute measures and initiated an A-level response to major public health emergencies, closed access to cities in many places, and suspended large-scale mass activities, which brought many enterprises into a downtime. As a result, the macro-economy was greatly impacted.[1] From the perspective of national economy structure, China's GDP in the first quarter of 2020 decreased by $6.8 \%$ year on year to 20650.4 billion yuan, for the first time, the economy appeared negative growth since China's reform and opening up. The primary industry dropped by $3.2 \%$, the secondary industry decreased most severely by $9.6 \%$, and the tertiary industry fell by $5.2 \%$.[2] Since the second quarter, the main economic indicators have stopped declining and began to stabilize, with a year-on-year growth of $3.2 \%$ in GDP. In the third quarter, the main economic indicators have recovered, with a year-on-year growth of $4.9 \%$. In the first three quarters, GDP increased by $0.7 \%$ year-on-year, the growth rates of the three industries all turned positive, of which the primary industry, the secondary industry and the tertiary industry grew by $2.3 \%, 0.9 \%$ and $0.4 \%$ respectively.
As for the demand side, due to the suspension of work and production during the epidemic period, the disposable income of residents declined. In the first half year, the per capita disposable income of residents in China was 15666 yuan, falling by $1.3 \%$, excluding price factors. Plus the influence of epidemic prevention and control policies during the Spring Festival, catering, tourism, film and television and other industries were in a semi-closed state, resulting in slack consumer demand. From the perspective of index of total retail sales of consumer goods, we can see that in the first quarter the index fell by $19 \%, 3.9 \%$ in the second quarter, and $7.2 \%$ in the first three quarters year on year. During the epidemic period, the production power and production capacity of enterprises declined. And the demand for raw materials decreased, in the first three quarters, PPI decreased by $2.0 \%$ year on year, and the demand of enterprises remained slack. However, from the perspective of supply side, with the orderly resumption of work and production, China's economy had been picking up, the industrial production got improved, the cumulative growth rate turned from negative to positive, and the service industry showed noticeable signs of recovery. In terms of agricultural supply, the epidemic in China was kept under control before spring farming. By April, there were only sporadic outbreaks in a few regions, and spring farming was rolling out in most regions, but the subsequent sales and transportation were still greatly affected by the epidemic. In order to guarantee the domestic food supply, the state adopted a series of policies. First, the Current Work Guidelines for 
Spring Farming Production was issued to guide the restoration of agricultural production order in different regions. Second, before the spring farming is carried out in large scale, the Ministry of agriculture and rural areas will announce the grain production target to Provincial Governments, and take the stable grain area as the binding indicator to ensure the stability of the whole year's grain area. Third, encourage farmers to restore growing double-cropping rice, raise the minimum purchase prices of early and mid-late indica rice, and expand capital investment from central and local departments to support the restoration of double cropping rice in main production areas. From the perspective of grain import and export, according to the statistics of the Ministry of agriculture and rural areas, in the first half he year, the import and export volume of China's agricultural products amounted to 116.68 billion US dollars, an increase of $7.4 \%$ year on year, of which the export volume decreased by $3.8 \%$ year on year, the import volume increased by $13.1 \%$ year on year, and the trade deficit was 45.84 billion US dollars, an increase of $30.9 \%$. Despite the outbreak of the epidemic, China achieved stable supply of agricultural products through keeping domestic production at a stable level and expanding imports, and people live an orderly life.

\subsection{Literature Review}

Zhang Bin (2020) concluded by analyzing the global and China's macroeconomic data that the impact of epidemic on global economy is far-reaching, although the economic pressure has been currently eased by administrative measures, the potential pressure will last for a long time. Qulili (2021), taking the development of contemporary Internet into consideration, proposed the new development opportunities of agricultural economy: the Internet and market demand should be integrated into the development of agricultural products marketing, so as to promote the long-term development of agricultural economy. Liu Wenhua (2021) put forward the development potential of "Internet plus Agriculture" through qualitative analysis, which is conducive to the optimization of agricultural economy structure, the integration of agricultural resources and the achievement of a comprehensive well-off society at an early date. Lv Lei (2020) believes that the rapid development of the Internet has not only brought impact to all industries but also provided development opportunities. All industries hope to empower traditional industries by taking advantage of Internet technology. As a large agricultural country, China's also needs to use new technologies to improve the production efficiency of agriculture industry. Xu Jiaxu (2021). At the beginning of 2020, the impact of the global epidemic on China's agricultural industry exposed the shortcomings of the development pattern of traditional agricultural economy. From the perspective of financial intelligent development pattern of agricultural supply chain, this paper puts forward a solution to the problem of financial development pattern of traditional agriculture, and proposes to grasp policy guidance so as to give full play to policy advantages, and to meet the service demand to as to seize development opportunities. Foreign scholar Degineh Lagiso (2020) believes that COVID-19 brought both opportunities and challenges to agricultural development. The government needs to take various benefits into consideration based on green economy, implement the fiscal policies that reduce taxes and increase government expenditure to enhance agricultural production and safety. Neetu Sharma (2020) believes that it is the COVID-19 and changed international situation that impact on the agricultural economy greatly. Therefore, a diversified agricultural system is needed, so that the agricultural economy can survive from the impact and the food safety can be improved. Francesco Pastore (2020) points out that the global job market is affected by the epidemic, and this impact will last for a long time, resulting in a decrease in per capita income and an increase in unemployment. Richard Simmons (2020) believes that COVID-19 will make the year of 2020 a turning point in the world economy. It weakens the established economic system of the century and has a huge influence on developed countries. Even the International Monetary Fund begins to question the measures of liberalization and debt reduction proposed in Washington Consensus.

\subsection{Research Approach}

The year of 2020 is the decisive year for building a moderately prosperous society for all the people in China. The people that live in poverty in China live on agriculture. And they mainly populate rural areas. In face of unfavorable impact, how to increase agricultural production is a difficult problem for China's agricultural industry. At the same time, people's pursuit of a better life is constantly improving. The development of various levels of agricultural products is also needed. Therefore, this paper will classify agricultural products according to different attributes, and conduct in-depth analysis of basic agricultural products, cash crops and high value-added agricultural products, and make relevant suggestions.

\section{HE ANALYSIS OF COVID-19'S IMPACT ON AGRICULTURE}

The impact of COVID-19 on the agricultural economy was enormous, especially in the transportation sector. The strict traffic blockade imposed throughout the epidemic period blocked the transportation and sales of agricultural products. As a result, problems of slow sales and falling prices arose, especially vegetables in season. On the demand side, because of the panic of consumers, there were problems like tight balance at short term and partially structural shortage. At the same time, the demand of export hurt because some export channels 
were blocked. In order to analyze the impact of COVID-19 on China's agriculture in a clearer and more direct way, in this paper, agricultural products are divided into three categories: basic agricultural products, cash crops and high value-added agricultural products, and the relationship between supply and demand and prices are discussed.

\subsection{Analysis of the Impact of Epidemic on the Market of Basic Agricultural Products}

In terms of basic agricultural products, there are mainly two points needed to focus: the supply-demand relationship and fluctuation of price of the three staple crops. Throughout the epidemic period, the overall supply of rice, wheat and corn in China was sufficient. However, due to the outbreak of the epidemic, some farmers were reluctant to sell, coupled with the interruption of logistics, acquisitions almost stalled and the price of products rose slightly. Luckily, the grain reserve of the state is sufficient, and the state put the grain reserve into the market, as a result, the price was basically kept at a relatively normal range. With the resumption of work and production going on, more and more enterprises that process rice and corn resumed business, and the increasing demand for grain led to a slight rise in price. Since summer, the epidemic situation in China has been under control. The food price is mainly affected by seasonal factors not epidemic factor. In March, the average purchase price of early indica rice was 1.19 yuan per gram, an increase by $0.8 \%$ year on year, late indica rice was 1.27 yuan, a decrease by $0.8 \%$ year on year, and japonica rice was 1.34 yuan, declining $4.3 \%$ year on year. By March in 2020, the market price of domestic wheat had been kept at 1.34 yuan per gram, and the corn price had increased by 0.02 yuan from 0.98 yuan per gram in January to 1 yuan per gram in March. In summer months, the wholesale price of staple crops in China fluctuated in a reasonable range due to seasonal factors. The price of rice fluctuated in a range from 1.20 to 1.27 yuan, the price of wheat remained around 1.17 yuan, and the highest price of corn went to 1.15 yuan per gram. For example, in June, the average purchase price of early indica rice was 1.20 yuan per gram, increasing $6.2 \%$ year on year, late indica rice was 1.29 yuan, decreasing $2.4 \%$ year on year, and japonica rice was 1.44 yuan, increasing $5.9 \%$ year on year. In mid-late June, the price of wheat kept rising nationwide. And the purchase price rose to 1.14-1.20 yuan per gram in general at the end of June. The wholesale price of corn remained around 0.96 yuan. In general, even during the most severe epidemic and the strictest control period, China's crop market was just affected slightly. Some farmers were not willing to sell grain, but the demand was weak, therefore, the supply was relatively sufficient and the supply-demand relationship matched in general. With the domestic situation stabilizing, the impact of the epidemic on China was mainly the fluctuation of international food prices of import and export.

\subsection{Analysis of the Impact of Epidemic on Cash Crops Market}

In terms of cash crops, this paper mainly studied four staple cash crops, namely soybean, cotton, sugarcane and sugar beet. At the beginning of the epidemic, all factories were in suspension, and the demand for soybean, a kind of primary raw material, decreased sharply. This change reflected in price was slight. This was because the suspension period coincided with soybean base grain purchase period, and the stocks in every production base were limited, in addition, the interruption of logistics made acquisition all the more difficult. Decreased demand and insufficient supply also led to the rise of soybean price potentially. Since the middle of February, more and more enterprises that engage in crushing crops began to resume business, some even back to normal business. The short-term supply-demand problem caused by insufficient labor and poor logistics at the early stage was eased, and the domestic supply of soybean meal and soybean oil remained stable, coupled with imports, the supply of China's soybean was sufficient. Since May, the demand and profit of crushing soybean have been increasing. The enterprises actively purchase soybean, and the relationship between supply and demand has stabilized. The promise of cotton market is different from that of soybean. At the beginning of the epidemic, due to the suspension of production, cotton was unsalable. In March, the average price of $3128 \mathrm{~B}$ cotton in China was 12195 yuan per ton, down $21.7 \%$ year on year. In Zhengzhou, the monthly settlement price of main futures contract of cotton (CF005) was 11512 yuan per ton, down $23.5 \%$ year on year.

The continuous development of epidemic in foreign countries greatly hit the export of textile industry, resulting in slack demand and continuous decline in summer cotton prices. Throughout the epidemic period, the reserve of cotton was sufficient, but the consumption was quite conservative. The price was kept at a low level, below 13000 yuan per ton, far lower than the average price of 13346.7 yuan per ton in winter of 2019. Regarding sugar crops, as harvest time in the southern sugarcane areas was just during the outbreak of epidemic, the harvest and transportation of sugarcane stalled. At the same time, due to the stagnation of the catering industry, the demand for sugar fell sharply, so the supply-demand relationship was basically stable. By the end of March, the country's accumulated sugar production was 9.81 million tons, a decrease of 90000 tons or $0.9 \%$ compared with the same period of last year, and the accumulated sugar sales was 4.77 million tons, a decrease of 120000 tons or $2.5 \%$ compared with the same period of last year; the sugar sales rate was $48.6 \%$, a decrease of $0.8 \%$ compared with the same period of last year. The gap 
between sugar production and demand is still deep. As the impact of the epidemic gradually weakened, since the third quarter, sugar production and sales has basically returned to normal. By the end of October, sugar factories in Xinjiang, Inner Mongolia and other beet sugar producing areas had all resumed business, with 432600 tons of sugar produced nationwide, an increase of 33800 tons over the same period of last year; 149700 tons of sugar sold, an increase of 13400 tons over the same period of last year. The whole situation of sugar production in China was stable.

\subsection{Analysis of the Impact of Epidemic on Cash Crops Market}

In terms of high-end agricultural products, there is no consistent definition of high-end agricultural products at home and abroad. The writer believes that high-end agricultural products are agricultural products with added value and high price. At the beginning of epidemic, the overall market demand was slack. From January to February, the total retail sales of social consumer goods decreased by $20.5 \%$ year-on-year, of which the retail sales of goods dropped by $17.6 \%$. From that, we can see a certain trend in the consumption of high-end agricultural products. In addition, the sales of high-end agricultural products mainly centered on offline, people were isolated at home at the beginning of epidemic. So it was a huge impact on offline retails. In terms of online sales, although online retail of agricultural products has been developed in recent years, it does not occupy a large market share in reality. The writer believes that this is because of the particularity of agricultural products. Agricultural products need to be fresh and have high quality. Online sales cannot meet the instant experience of consumers, so the best choice for consumers is offline retail. During the epidemic period, high-end agricultural products also showed the characteristic of big price elasticity, which also reflected the decline in demand. The price of some products can even drop by $50 \%$. For example, the price of imported cherries has dropped from an average price of 64 yuan per gram to 30 yuan per gram. Similarly, income and employment will also affect the sales of high-end agricultural products. According to the data of the National Bureau of statistics, the unemployment rate rose to a high of $6.2 \%$ in February, which is 0.9 percentage points higher than that in January and the same period in 2019. In the first quarter of 2020, the per capita disposable income of residents decreased by $3.9 \%$, and in the second quarter decreased by $1.3 \%$. Unfavorable employment and income situation will also affect the consumption of high-end agricultural products in the market.[3]In addition, the wait-and-see attitude people took towards the uncertain future market during the epidemic period and the behavior of reducing expenditure were also in line with the consumption trend of agricultural product in previous article.

\section{CONCLUSION AND SUGGESTIONS}

In the epidemic situation, although China's response was rapid and the control measures were relatively effective, there still existed some problems. However, thanks to the state's macro-control, the stable and orderly operation of the agricultural market was realized. In view of the problems exposed in China's agricultural products market during the epidemic period, the following suggestions are put forward:

In terms of basic agricultural products, they were impacted at the beginning of epidemic, especially the food supply security and transportation. It is hereby proposed:

In the short run, it can increase the number of grain reserve bases and enrich the methods of grain reserve, such as canned food and air dried food. In order to prevent the blockage of cities and severance of diplomatic relations in the future, all localities should collect grain locally.

In the long run, the source of the above problems still lies in the inefficiency of agricultural production in China. At present, the quality of seeds in China is substandard. We should increase investment in science and technology, develop seed with the help of science and technology, select more high-yield and more adaptable varieties, and improve the efficiency of the agricultural production in China.[5]

As for cash crops, due to the suspension of factories, a large number of raw materials were overstocked, which increased the storage cost. We can further optimize the industrial chain, bridge between the supply side and demand side, and enrich the processing methods from raw materials to primary raw materials. In this paper, the following suggestions are proposed.

Further promote processing technology, set up agricultural cooperation, so that farmers can exercise simple primary processing, which can not only increase farmers' income, but also extend purchase channels for factories, as well as promote a benign competition for market.

Further improve the national regulatory system, establish a unified information platform, expand information circulation channels, and make farmers sell products in a more convenient way.

There are three main problems of high-end agricultural products. First, food safety is difficult to guarantee. Second, marketing mode is single. Third, industrial chain remains to be optimized. Therefore, in this paper the following suggestions are put forward.

On the one hand, the state is supposed to establish a unified market quality testing standard, and establish a professional certification body, and conduct regular sampling inspection to ensure food safety. On the other 
hand, enterprises should cooperate with the quality inspection work to better grade the sales. And a good market order should be established. [5]

Combine various online platforms to extend sales channels and enrich consumers' purchasing experience. Complete the construction of website, make the production process transparent, so that consumers can see the whole process from planting to picking and logistics, let consumers buy and use products with a peace of mind.[6]

Value the brand marketing. For the characteristics of high-end agricultural products, apart from the high quality, the main characteristic is its added value. So we should value the brand building, especially some brands with regional characteristics, such as Yangcheng Lake hairy Crabs, ManJiang Red Crayfish and so on. We should focus on quality, strengthen publicity, and pinpoint positioning.

Associate farmers according to the region, preliminarily integrating local resources and then docking with the platform directly. In this way, we can don't need middlemen, so we can better control the quality of products.

\section{REFERENCES}

[1] Zhang Bin." The Impact of COVID-19 Epidemic on Macroeconomy and the Hedging Effect of Fiscal
Policy Evaluation." Industrial Technology Economics 10(2020).

[2] Ma Wan qing. Analysis of the impact of COVID-19 on China's macro economy. Journal of Hubei University of Economics (Humanities and Social Sciences Edition) 9(2020).

[3] Pastore, F., et al. "Pandemic and The Labour Economy." (2020).

[4] Lagiso, D. "Challenges and Opportunities of Covid-19 in Agricultural Economy: The Case of Ethiopia." Journal of Asian and African studies 65(2020):2020.

[5] Sharma, N. "Innovative practices for food security \& sustainable agriculture: a forecasting challenge to the post-pandemic economy." Turn Over a New Leaf. Innovations, Pseudo-Innovations and Corporate Social Responsibility Turn Over a New Leaf. Innovations, Pseudo-Innovations and Corporate Social Responsibility THE BOOK OF ABSTRACTS Kraków 20202020.

[6] Lv Lei." Analysis of the Impact of Internet Economy Development on Agricultural Economy ". Farm Economy Management No.296.11(2020):33-34. 